\title{
Digby Tantam: Autism Spectrum Disorders Through the Life Span
}

\author{
Jessica Kingsley Publishers, London. ISBN: 9781843109938
}

\author{
C. P. Whyatt
}

Received: 4 July 2012/ Accepted: 28 July 2012/Published online: 8 August 2012

(C) Royal Academy of Medicine in Ireland 2012

In his current book, Professor Digby Tantam draws upon his long established career and clinical expertise to provide a comprehensive overview of autism spectrum disorders across the lifespan. This extensive book covers a wide range, taking the reader on a journey through the underlying theory to a practical understanding of autism spectrum disorders in a clinical setting.

Drawing on the traditional understanding of autism spectrum disorders from the seminal work of Kanner and Asperger, and current research, Digby Tantam provides the reader with a well-researched, objective summary of the neurophysiological, genetic and psychosocial theoretical aspects of autism spectrum disorders. Touching on a vast range of symptoms, Digby not only highlights the prominent social and cognitive facets of autism spectrum disorders, but also the arguably underrepresented symptoms, often associated with age. In particular, he outlines how symptoms of autism spectrum disorders are inherently variable, inevitably interact, and can be directly shaped by age.

This detailed outline of the progression of autism spectrum disorders across the lifespan is a clear strength of this latest book. Specific sections outlining the presentation and thus treatment of Kanner Syndrome, Asperger's Syndrome and atypical Asperger's Syndrome in infancy, middle childhood and adolescence provide the reader with a thorough understanding of the nuances of autism spectrum disorders.

Furthermore, by setting autism spectrum disorders within the context of overlapping disorders such as ADHD and speech and language disorder, Digby Tantam highlights both the similarities and differentiating factors. A detailed picture of the complexities and difficulties associated with partialling out disorders is outlined, facilitating clinical practice and appropriate treatment plans.

This well-written book, interspersed with case studies and personal comments from Professor Digby Tantam is a pleasure to read, helping to establish the relationship between basic theory, basic science and autism spectrum disorders in a clinical context. The range and detail of, "Autism Spectrum Disorders Through the Lifespan" set it apart, and I would highly recommend this book for anyone who wishes to have a comprehensive overview of autism spectrum disorders. At $£ 75.00$, this book belongs on the bookshelf of researchers and clinicians alike. 